\title{
Thermal Growth and Decomposition of The Methylnaphthalenes
}

\author{
Jun Yang and Mingming Lu*
}

Number of pages: 4 including the cover

Number of figures: 5

Number of tables: 0 


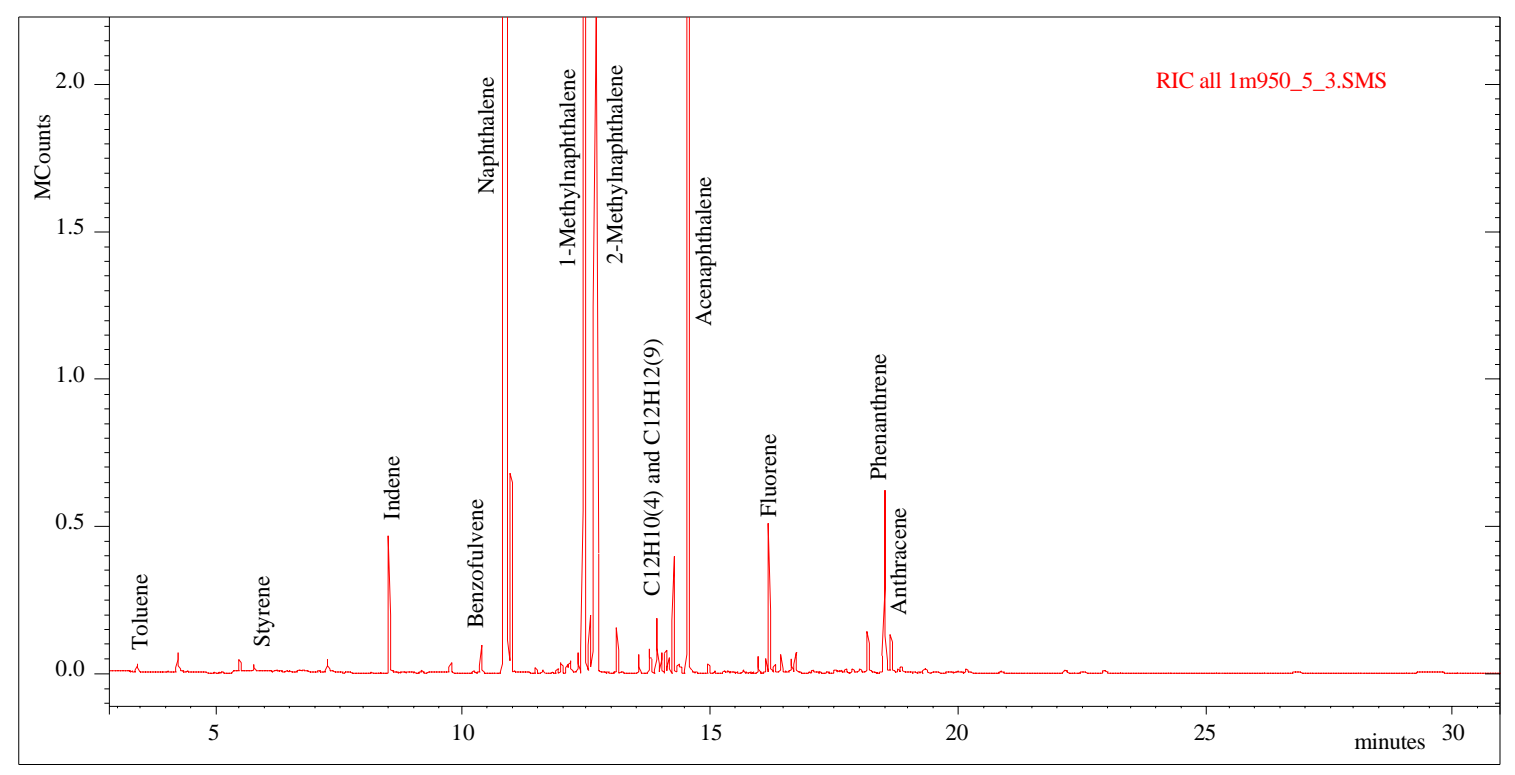

S-1 The chromatography of products in 1-MN pyrolysis

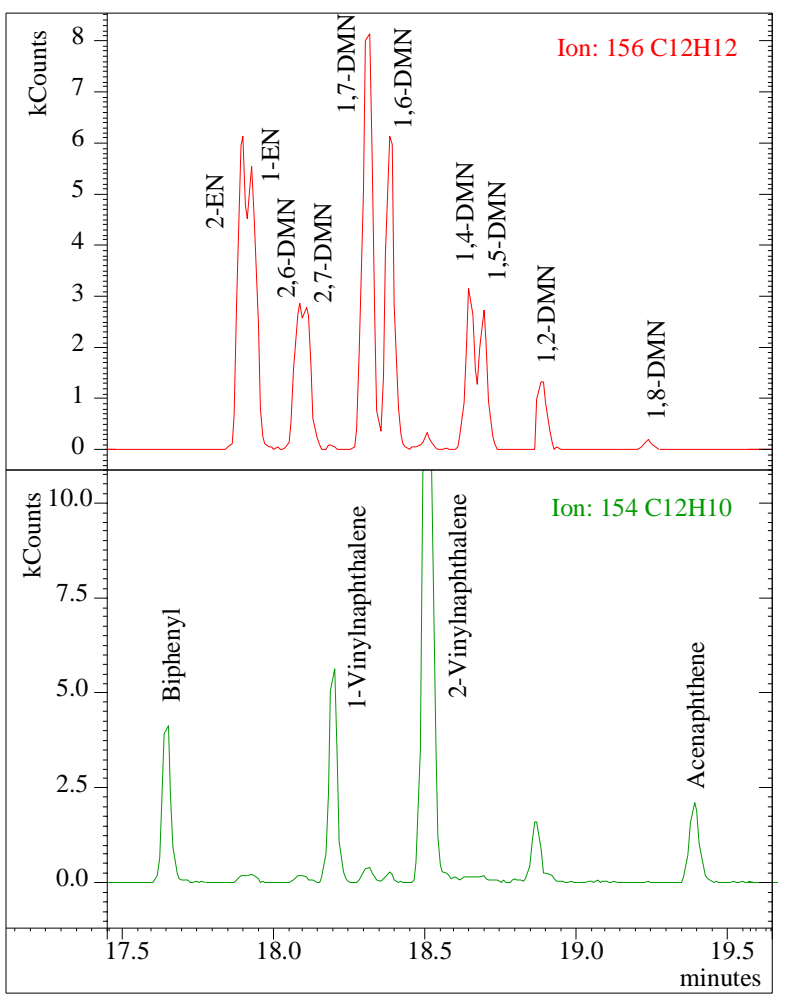

S-2 The selective ion chromatography for C12H12 and C12H10 in 1-MN pyrolysis 


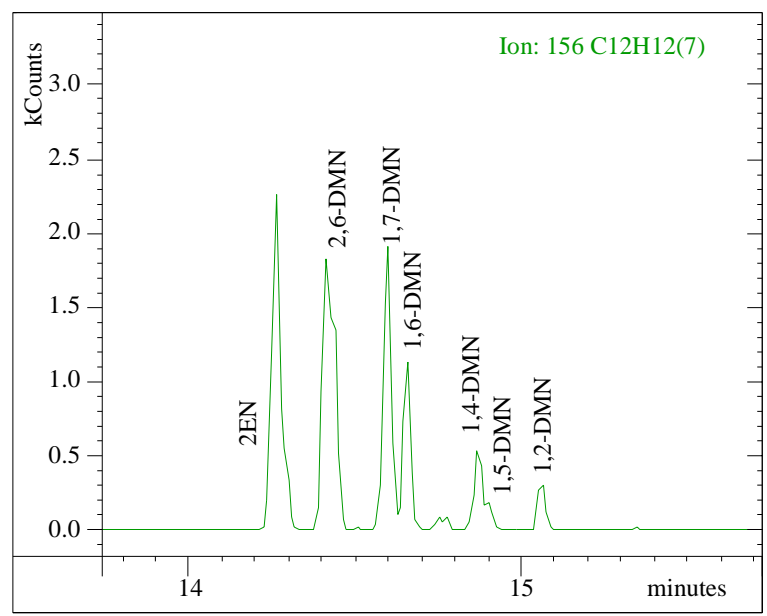

S-3 The selective ion chromatography for C12H12 in 2-MN pyrolysis



S-4 The chromatography of products in 2-MN oxidation. 1 benzene; 2 toluene; 3 ethylbenzene; 4 p-xylene; 5 phenylacetylene; 6 styrene; 7 benzaldehyde; 8 benzofuran; 9 indene; 10 benzofulvene;10naphthalene; $112-\mathrm{MN}$; 12 1-MN; 13C12H10s \& C12H12s; 14 acenaphthylene; 15 2-naphthaldehyde; 16 fluorene; 18 phenanthrene; 19 anthracene. 


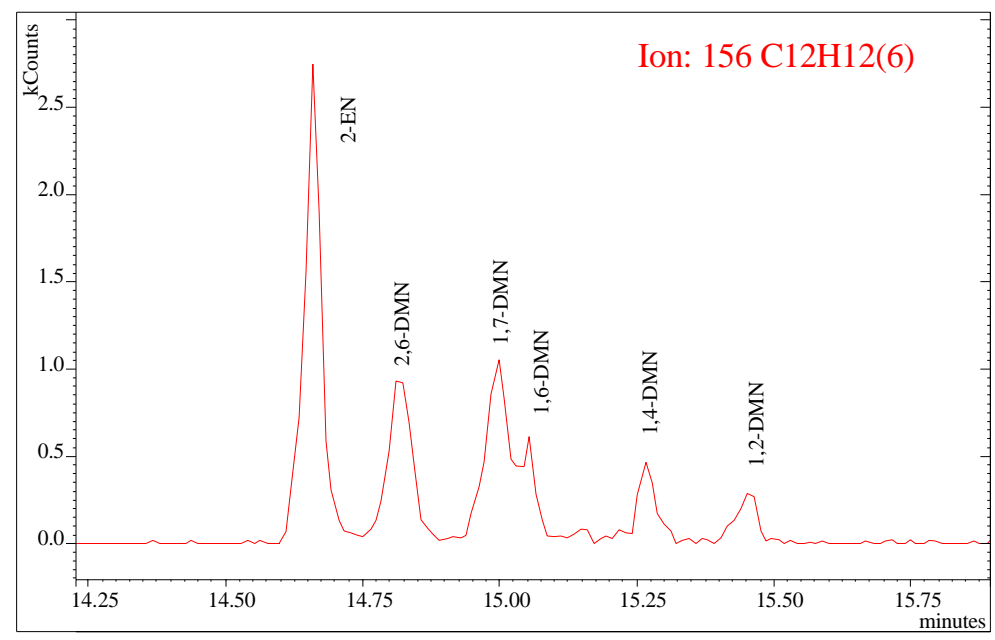

S-5 The selective ion chromatography for $\mathrm{C} 12 \mathrm{H} 12$ in 2-MN oxidation 